\title{
KNOWLEDGE AND PRACTICE ON RABIES IN AN URBAN COMMUNITY OF MANIPUR, INDIA
}

\author{
Jalina Laishram¹, Susmita Chaudhuri², H. Sanayaima Devi³, Shantibala Konjengbam ${ }^{4}$
}

${ }^{1}$ Demonstrator, Department of Community Medicine, Regional Institute of Medical Sciences, Imphal, Manipur, India.

${ }^{2}$ Post Graduate Trainee, Department of Community Medicine, Regional Institute of Medical Sciences, Imphal, Manipur, India.

3Professor, Department of Community Medicine, Regional Institute of Medical Sciences, Imphal, Manipur, India.

${ }_{4}^{4}$ Associate Professor, Department of Community Medicine, Regional Institute of Medical Sciences, Imphal, Manipur, India.

\begin{tabular}{l}
\hline ABSTRACT \\
BACKGROUND \\
Rabies is a zoonotic disease, which affects all warm blooded animals including human. It is a neglected disease of poor and \\
vulnerable population, whose deaths are rarely reported.
\end{tabular}

\section{OBJECTIVES}

To assess the knowledge and practice on rabies among the adult residents in an urban community and to determine the association between knowledge on rabies and variables such as age, sex, education and income.

\section{MATERIALS AND METHODS}

A cross-sectional study was conducted among the adult residents in an urban community in Imphal West District of Manipur, India, in November 2013 to January 2014. Data were collected using structured interview schedule after obtaining informed consent. Median score was taken as a cut-off for deciding adequacy of knowledge.

\section{STATISTICAL ANALYSIS}

Descriptive statistics like mean, standard deviation and percentages were used. To determine the association, Chi-square test was used and a p-value of $<0.05$ was taken as significant.

\section{RESULTS}

A total of 350 respondents participated in the study. Mean age was $32.97( \pm 13.02)$ years. Majority $(42.6 \%)$ of the respondents belonged to the age group of 20-29 years. Male and female respondents were equal in number. Three hundred and forty respondents (97.1\%) had ever heard of rabies, but only $8.6 \%$ knew that it was caused by a virus. More than half of the respondents, i.e. 175 had inadequate knowledge (51.5\%). Nearly 88\% were aware that rabies was a fatal disease. Age, educational status and income were significantly associated with adequate knowledge. Of all the respondents, $98(28 \%)$ have at least one pet dog or cat and only $1 \%$ of the pets were vaccinated against rabies.

\section{KEYWORDS}

Animal Bite, Dog Bite, Rabies, Cross Sectional Study, Awareness.

HOW TO CITE THIS ARTICLE: Laishram J, Chaudhuri S, Devi HS, et al. Knowledge and practice on rabies in an urban community of Manipur, India. J. Evolution Med. Dent. Sci. 2016;5(37):2234-2237, DOI: 10.14260/jemds/2016/519

\section{INTRODUCTION}

Rabies is a zoonotic disease that is caused by a virus. The disease affects domestic and wild animals and it spreads to human through close contact with infectious material, usually saliva, via bites or scratches. Rabies is present on all continents with the exception of Antarctica, but more than $95 \%$ of human deaths occur in Asia and Africa. Once symptoms of the disease develop, rabies is nearly always fatal. More than 55,000 people die of rabies every year, mostly in Asia and Africa; $40 \%$ of people who are bitten by suspect rabid animals are children under 15 years of age. ${ }^{1}$ In India 15 million people are bitten by animals, mostly dog bites every year and need post exposure prophylaxis. Since 1985, India has reported 25000-30000 human deaths from rabies annually. ${ }^{2}$

\section{Financial or Other, Competing Interest: None.}

Submission 07-03-2016, Peer Review 17-04-2016,

Acceptance 23-04-2016, Published 09-05-2016.

Corresponding Author:

Dr. Jalina Laishram,

Thangmeiband Lairenhanjaba Leikai,

Imphal-795004,

Manipur.

E-mail: jalinalaishram@yahoo.co.in

DOI: $10.14260 /$ jemds/2016/519
Majority of people who die of rabies are of poor or low socio-economic status. ${ }^{3}$ In India there is no organised surveillance system of human and animal cases of rabies, the actual number of deaths may be much higher. The latest figure projected from the National Multicentre Rabies survey conducted in 2004 by the association for prevention and control of Rabies in India in collaboration with World Health Organisation is 205656 deaths from rabies per year.4 Most animal bites in India (91.5\%) are by dogs, of which about $60 \%$ are strays and $40 \%$ pets. The incidence of animal bites is 17.4 per 1000 population. A person is bitten every 2 seconds and someone dies from rabies every 30 seconds. ${ }^{2}$

One of the reasons the disease has been neglected is because "Deaths are scattered" and never amount to the kind of crisis that get epidemics top billing. Indeed, experts say that the main constraint to rabies elimination in India is the lack of coordination and the lack of a comprehensive national programme. 5 To the best of our knowledge, no study regarding rabies has been conducted so far in Manipur. Hence, this study was undertaken with the objectives to assess the knowledge and practice on rabies among the adults in an urban community in Manipur and to determine the association between knowledge on rabies and some selected variables of interest like age, education, monthly income. 


\section{MATERIALS AND METHODS}

A cross-sectional study was conducted among the adult residents in an urban community of Imphal, Manipur, during November 2013 to January 2014. This urban community is located in the urban field practice area of the Department of Community Medicine, Regional Institute of Medical Sciences (RIMS), Imphal, Manipur. Adults aged 18 years and above and who are permanent residents of the area were included in the study. There were a total of 370 families in this community. One adult member aged 18 years and above who gives consent was selected from each family to participate in the study. In case when there were more than one adult available in a family at the time of our visit, we selected one by lottery method. We intended to cover all the families in this community, so sample size was not calculated. Those who refused to participate and those who could not be contacted even after 3 successive visits were excluded from the study.

Data were collected using structured interview schedule which consists of socio-demographic variables, questions on knowledge and practice on rabies. Score was given for 12 questions on knowledge. The obtainable score ranges from 0 to 35. Median score was taken as a cut-off for deciding the adequacy of knowledge. Those who obtained less than and equal to median score were considered as having inadequate knowledge and those who obtained more than median score were considered having adequate knowledge.

The study was approved by the Institutional Ethics Committee, RIMS, Imphal, Manipur. Verbal informed consent was obtained from all the participants. Those who refused to participate and those who could not be contacted even after 3 successive visits were excluded from the study. Confidentiality was maintained.

Data were checked for consistency and completeness and entered in SPSS 16. Descriptive statistics like mean, standard deviation and percentages were used to describe the findings. Analysis was done using Chi-square test and a pvalue of $<0.05$ was taken as significant.

\section{RESULTS}

A total of 350 respondents participated in our study. Out of 370 families, 8 refused to participate and members of 12 families could not be contacted even after 3 consecutive visits. Response rate was $94.6 \%$. Mean age of respondents was $32.97 \pm 13.02$ years. Males and females were equal in number. Little more than half of the respondents (53.1\%) were Hindu by religion. Majority of them had education level between class X-XII (41.8\%). More than 4 in 10 participants were selfemployed and majority (72.3\%) of them had a monthly family income of ten thousand rupees and more.

Median knowledge score obtained by the respondents was 11 with maximum of 30 and minimum of 0 . More than half of the respondents, i.e. 175 had inadequate knowledge (51.5\%). Majority of the respondents [340 (97.1\%)] had ever heard of rabies and all of them knew that dogs harbour rabies organism. But only $8.6 \%$ of them knew correctly that the causative organism was a virus. Almost 9 out of 10 participants told that bite of suspected animals like dogs, cats could spread this disease and $67 \%$ respondents told that head was the most dangerous site of bite. Almost 9 in 10 participants told that the disease was fatal. Majority, i.e. 73\% of them said that washing with water and antiseptics should be done following animal bite.
Almost half of the respondents said that rabies could be prevented by vaccination. When asked whom they would consult after a dog bite or any bite by a suspected rabid animal, more than $92 \%$ said that they would consult a doctor or go to a hospital for treatment. Only $9.1 \%$ knew about preexposure anti-rabies vaccination for human. When asked about the symptoms of rabies in dog, aggressive behaviour and excessive salivation were the most common responses (Table 1).

Among the respondents, $28 \%$ of them had pets and dog constituted the majority of them (68\%). But only $1 \%$ of the dogs were vaccinated. Only $1.1 \%$ of the respondents had ever been bitten by a dog and one-fourth of them had washed the wound with water, another one-fourth had washed with water and antiseptics. But half of those bitten by a dog did not wash the wound (Table 2).

Respondents aged 60 years and more had more adequate knowledge compared to other age groups and it was statistically significant. There was no association between gender and knowledge. When we see the association between knowledge and educational status, it was found that those who were graduates and above had higher knowledge. Those respondents whose monthly income was more than ten thousand rupees had more knowledge and that was found to be statistically significant (Table 3).

\begin{tabular}{|c|c|}
\hline Knowledge Questions & N (\%) \\
\hline \multicolumn{2}{|l|}{ Have you Ever Heard of Rabies? } \\
\hline Yes & $340(97.1)$ \\
\hline No & $10(2.9)$ \\
\hline \multicolumn{2}{|l|}{ Which Organism Causes Rabies? } \\
\hline Correct Response (Virus) & $29(8.6)$ \\
\hline Incorrect Response & $311(91.4)$ \\
\hline \multicolumn{2}{|l|}{ Which Animal Harbours Rabies Organism?* } \\
\hline Dog & $340(97.1)$ \\
\hline Cat & $75(21.4)$ \\
\hline Bat & $6(1.7)$ \\
\hline Monkey & $5(1.4)$ \\
\hline \multicolumn{2}{|l|}{ How does Rabies Spread? * } \\
\hline Bite of Suspected Animals (Dog, Cat, etc.) & $314(89.7)$ \\
\hline Licks on Broken Skin & $3(0.9)$ \\
\hline $\begin{array}{l}\text { Contamination of Mucous Membrane with } \\
\text { Saliva }\end{array}$ & $62(17.7)$ \\
\hline \multicolumn{2}{|l|}{ What are the Danger Sites of Bite? ${ }^{*}$} \\
\hline Head & $236(67.4)$ \\
\hline Face & $68(19.4)$ \\
\hline Neck & $9(2.6)$ \\
\hline \multicolumn{2}{|l|}{ Is the Disease Fatal? * } \\
\hline Yes & $299(87.9)$ \\
\hline No & $40(11.8)$ \\
\hline Don't know & $1(0.3)$ \\
\hline \multicolumn{2}{|c|}{$\begin{array}{l}\text { What should be done following Dog/Cat/Other Suspected } \\
\text { Animal Bite? * }\end{array}$} \\
\hline Wash with Water only & $2(0.6)$ \\
\hline Wash with Soap and Water & $4(1.1)$ \\
\hline Wash with Antiseptics & $251(73.8)$ \\
\hline Injection TT & $241(70.8)$ \\
\hline \multicolumn{2}{|l|}{ Can Rabies be prevented by Vaccination? } \\
\hline Yes & $168(49.4)$ \\
\hline No & $168(49.4)$ \\
\hline Don't Know & $4(1.2)$ \\
\hline
\end{tabular}




\begin{tabular}{|l|c|}
\hline $\begin{array}{l}\text { Whom will you Consult After Dog/Cat/other Suspected } \\
\text { Animal Bite }{ }^{*}\end{array}$ \\
\hline Doctor/Hospital & $314(92.3)$ \\
\hline Local Quack/Traditional Healer & $145(42.6)$ \\
\hline No one & $2(0.50)$ \\
\hline How to Avoid Rabies Infection? ${ }^{*}$ & $31(9.1)$ \\
\hline Pre-exposure Vaccination of Human & $217(63.8)$ \\
\hline Avoiding Animal Contact & $256(75.2)$ \\
\hline Anti-rabies Vaccination of Animals & $5(1.4)$ \\
\hline Don't know & $267(78.5)$ \\
\hline What are the Symptoms of Rabies in Dogs? ${ }^{*}$ \\
\hline Aggressive & $93(27.3)$ \\
\hline Bites unusual objects & $62(18.2)$ \\
\hline Change in Voice & $171(50.2)$ \\
\hline Excessive Salivation & $2(0.6)$ \\
\hline Paralysis & \\
\hline $\begin{array}{l}\text { After a Dog has Bitten you will you kill it if Rabies is } \\
\text { suspected? }\end{array}$ & $10(2.9)$ \\
\hline Yes & $327(96.2)$ \\
\hline No & $3(0.9)$ \\
\hline Don't know 1: Knowledge on Rabies \\
\hline \multicolumn{2}{|l|}{} \\
\hline
\end{tabular}

*Multiple answers allowed

\begin{tabular}{|l|c|}
\hline Practice Questions & N (\%) \\
\hline Do you have any Pet Animal? & $98(28.0)$ \\
\hline Yes & $252(72.0)$ \\
\hline No & $31(31.6)$ \\
\hline If yes, which Animal? & $67(68.3)$ \\
\hline Cat & $1(1.0)$ \\
\hline Dog & $97(99.0)$ \\
\hline Are your Pets Vaccinated for Rabies? & $4(1.1)$ \\
\hline Yes & $346(98.9)$ \\
\hline No & \\
\hline Have you ever bitten by Dog/Cat? & $1(25.0)$ \\
\hline Yes & $1(25.0)$ \\
\hline No & $2(50.0)$ \\
\hline If yes, what did you do as First Aid? \\
\hline Wash with Water \\
\hline Wash with Antiseptic Solution \\
\hline Injection Tetanus Toxoid \\
\hline \multicolumn{2}{|c|}{ Table 2 ?actice on Rabies } \\
\hline
\end{tabular}

\begin{tabular}{|c|c|c|c|c|}
\hline \multirow[b]{2}{*}{ Variables } & \multicolumn{2}{|c|}{ Knowledge } & \multirow{2}{*}{$\begin{array}{c}\mathrm{X}^{2} \\
\text { value }\end{array}$} & \multirow{2}{*}{$\begin{array}{c}\text { P- } \\
\text { value }\end{array}$} \\
\hline & $\begin{array}{c}\text { Inadequate, } \\
\mathbf{n}(\%)\end{array}$ & $\begin{array}{c}\text { Adequate, } \\
\text { n(\%) }\end{array}$ & & \\
\hline \multicolumn{5}{|c|}{ Age (Years) } \\
\hline$<20$ & $10(43.5)$ & $13(56.5)$ & & \\
\hline $20-29$ & $62(44.0)$ & $79(56.0)$ & & \\
\hline $30-39$ & $50(58.1)$ & $36(41.9)$ & 12 & 0.02 \\
\hline $40-49$ & $20(54.1)$ & $17(45.9)$ & & \\
\hline $50-59$ & $27(71.1)$ & $11(28.9)$ & & \\
\hline \multirow[t]{2}{*}{$\geq 60$} & $5(35.7)$ & $9(64.3)$ & & \\
\hline & Sex & & & \\
\hline Male & $86(51.5)$ & $81(48.5)$ & 0.37 & \\
\hline Female & $88(51.2)$ & $84(48.8)$ & & 1.0 \\
\hline \multicolumn{5}{|c|}{ Educational Status } \\
\hline Illiterate & $30(55.6)$ & $24(44.4)$ & & \\
\hline $\begin{array}{c}<\text { Class } 10 \\
\text { pass }\end{array}$ & $76(61.5)$ & $47(38.5)$ & 13 & 0.000 \\
\hline $\begin{array}{l}\text { Class } 10- \\
12 \text { pass }\end{array}$ & $62(44.6)$ & $77(55.4)$ & & \\
\hline $\begin{array}{l}\text { Graduate } \\
\text { and above }\end{array}$ & $7(29.2)$ & $17(70.8)$ & & \\
\hline
\end{tabular}

\begin{tabular}{|c|c|c|c|c|}
\hline \multicolumn{2}{|c|}{ Income (₹/Month) } & & & \\
\hline $\begin{array}{c}<000 \\
\begin{array}{c}5000- \\
9999\end{array}\end{array}$ & $54(46.2)$ & $7(53.8)$ & & \\
\hline $\begin{array}{c}10000- \\
14999\end{array}$ & $64(53.3)$ & $56(46.7)$ & & \\
\hline $\begin{array}{c}15000 \\
\text { and above }\end{array}$ & $50(40.3)$ & $74(59.7)$ & & 0.00 \\
\hline \multicolumn{5}{|c|}{ Table 3: Association Between Knowledge } \\
and Selected Variables
\end{tabular}

\section{DISCUSSION}

This study showed that majority of the respondents had heard about rabies. Majority (97.1\%) of them said that dog harbours rabies organism, which was consistent with the findings of Piyaphenee et al 6 , Mitabug et al 7 , Singh et al. ${ }^{8}$ Almost 9 in 10 of the participants told that bite of the dog could spread the disease, which was consistent with Piyaphenee et $\mathrm{al}^{6}$, Mitabug et al ${ }^{7}$, Prakash et al. ${ }^{9}$ Eighty seven percent respondents told that rabies was a fatal disease, which was concurrent with the finding where $84.9 \%$ of the respondents said that rabies could lead to death. ${ }^{6}$ Two-third of the respondents said that head was the most dangerous site of bite, which was in contrast with Prakash et al. ${ }^{9}$

In our study $49.4 \%$ of respondents said that rabies could be prevented by vaccination which was in contrast with one study. ${ }^{6}$ which found almost $90 \%$ of the respondents had the idea that vaccination could prevent rabies, but similar with the finding of Prakash et al. ${ }^{9}$ In our study, nearly $1 \%$ of the respondents said that they should wash the bite wound with either water or water and soap which is in contrast with the study findings where more than $50 \%$ of them were aware of it.6,8-11 In this study, $92.3 \%$ respondents said that they would consult a doctor or go to a hospital after a dog bite or bite by other suspected rabid animals. This was much higher than that reported by Singh et al $^{8}$ where only $36.4 \%$ would like to visit a doctor.

Our study showed that $28 \%$ of the respondents who own pets and dog was the most common which was comparable to other studies.6,9 Only $1 \%$ of the pets were vaccinated in this study, which was in contrast to a study. ${ }^{9}$ where $52 \%$ of the respondents got their pets vaccinated. Only $1 \%$ of the respondents had been bitten by dogs and only $25 \%$ of them washed the wound with water, which was in contrast with other study finding.6,9,12,13,14 Since the number of respondents ever bitten by a dog is very less, this finding should be interpreted cautiously.

Respondents aged 60 years and above had more adequate knowledge and it was statistically significant. This might be attributed to their life experiences. Those respondents who were below 30 years had better knowledge than those aged 30-59 years. As younger people are more exposed to mass media and this could have influenced their knowledge. Those who were graduates and above had more knowledge as compared to other group and this came out as expected as education and knowledge go hand-in-hand.

Those respondents whose monthly income was more than ten thousand rupees had more adequate knowledge and it was found to be statistically significant as those from higher socio-economic status tend to be more educated and are supposed to be more knowledgeable. 


\section{CONCLUSION}

Though majority of the respondents had ever heard of rabies, more than half of them had inadequate knowledge on rabies. Knowledge was found to be statistically associated with age, educational status and monthly family income. Though people knew that dog bite could cause rabies, vaccination of pets for rabies was low in this community. The strengths of this study are that it is the first study in Manipur regarding knowledge and practice on rabies and our study findings can be generalised to any urban community in Imphal, Manipur. Confining our study to only one urban community was a limitation of the study. We recommend that a study with larger sample size including both urban and rural areas should be conducted. Awareness about rabies can be increased by undertaking IEC activities in print and electronic media and by undertaking targeted awareness campaigns.

\section{REFERENCES}

1. WHO Rabies. Available at: www.who.int/mediacentre/factsheets/fs099/en/. Accessed on 25 Nov, 2013.

2. Sudarshan MK. Assessing burden of rabies in India. WHO sponsored national multi-centric rabies survey (May 2004). AssocPrev Control Rabies India J 2004;6:44-5.

3. Ghosh TK. Rabies. Proceedings of IX national conference of paediatrics infectious diseases, Chennai, India. 2006.

4. Desmukh RA. Rabies. Pune (India): Yogaksema department of virology, haffkine institute, 2004.

5. WHO. India's ongoing war against rabies. Available at: www.who.int/bulletin/volumes/87/12/09-021209/en/. Accessed on 26 Nov, 2013.
6. Piyaphanee W, Shantavasinkul P, Phumratanaprapin W, et al. Rabies exposure risk among foreign backpackers in Southeast Asia. Am J Trop Med Hyg 2010;82(6):1168-71.

7. Matibag GC, Kamigaki T, Kumarasiri PV, et al. Knowledge, attitudes, and practices survey of rabies in a community in Sri Lanka. Environmental Health and Preventive Medicine 2007;12(2):84-9.

8. Singh US, Choudhary SK. Knowledge, attitude, behaviour and practice study on dog-bites and its management in the context of prevention of rabies in a rural community of Gujarat. Indian J Community Med 2005;30(3):81-3.

9. Prakash M, Bhatti VK, Venkatesh G. Rabies menace and control-an insight into knowledge, attitude and practices. Medical Journal Armed Forces India 2013;69(1):57-60.

10. Agarvval N, Reddaiah VP. Knowledge, attitude and practice following dog bite: a community-based epidemiological study. Health Popul Perspect Issues 2003;26(4):154-61.

11. Chowdhury R, Mukherjee A, Naskar S, et al. A study on knowledge of animal bite management and rabies immunization among interns of a government medical college in Kolkata. Int J Med Public Health 2013;3(1):1720.

12. Ramos ME, Bravo LC. Knowledge, attitudes and practices of the community regarding animal bites and rabies. PIDSP J 2004;8:24-32.

13. Hampson K, Dobson A, Magai K, et al. Rabies exposures, post-exposure prophylaxis and deaths in a region of endemic canine rabies. Plos Negl Trop Dis 2008;2:e339.

14. Robertson K, Lumlertdacha B, Franka R, et al. Rabiesrelated knowledge and practices among persons at risk of bat exposures in Thailand. Plos Negl Trop Dis 2011;5(6):e1054. 